\title{
Criteria for courtroom speech cogency
}

\author{
Arastun Aliyar oglu Gasimov
}

DOI: 10.18355/XL.2018.11.04.12

\begin{abstract}
The relevance of the research problem is driven by the modern discourse in legal culture and legal linguistics. Thus, the article discusses the purposes and characteristics of a courtroom speech as a subtype of public speaking, the methods, and techniques of argumentation, means of courtroom speech consistency and influence, basic techniques of verbal behaviour of a forensic orator. Thus, the qualities of courtroom speech for cogency are determined. Furthermore, the study characterizes the speech-making features of a public prosecutor as well as defense attorney and judge. The practical value is that the paper provides recommendations concerning the selection and use of language means and the prevention of speech errors.
\end{abstract}

Key words: public speaking, courtroom speech, rhetoric, cogency, speech-making features of trial participants

\section{Introduction}

One of the key concepts of legal linguistics is the concept of discourse (Solan, 2017; Matoesian, 2017; Gibbons, 2014; Oxburgh, 2015; Goodrich, 1984). As a process, discourse is connected to human mental activity - language and speech are used as a means of expressing human mind (Simpson, 2016), while the intensification of verbal and cogitative activities of all discourse participants determines its interactive nature (Titscher et al., 2013; Mikhail, 2011; Hargitt, 2013).

Legal linguistics uses the notion of legal discourse and its variant - courtroom discourse. The concept of legal discourse is related to a broader communicative sphere. We adhere to the definition of courtroom discourse as a complex, manyvoiced system with a large number of participants, carrying out functions assigned to them by institutional rules (Wagner, Cheng, 2011; Bednarek, 2016).

The courtroom discourse is closely related to didactics since court decision texts serve to maintain law and order, civil rights protection, help to spread legal knowledge (Marsh, Cochrane, Melville, 2004; Strauber, 2016). Legal discourse uses the generated during religious, educational and pedagogical discourse practice ideas of moral categories (Morris, 2000) and has educational and didactic value due to the publicity of the decisions (Rogers et al., 2016; Paterson, 2011). The moral feelings of an individual contribute to the prevention of crime (Garver, 1998).

As part of the study of written legal texts, one can solve the problem of understanding and interpretation of legislation (Tiersma, 1999), consider stylistic features of legal documents (Mattila, 2016), and investigate the problem of the effective use of the terminology (Witczak-Plisiecka, 2009). Considering a legal text as an integral, complete product, having a clear structure, scientists at the same time point out its involvement into common linguistic and social context and external systems 
(Gibbons, 2014).

In the studies, oral legal discourse is presented as a contact communication, so its interactive character is reflected in the corresponding terminology (Coulthard, 2014). Legal discourse includes its more specific types, such as law enforcer discourse, prosecution and defense discourse, judge discourse, oral speech in law institutions, etc. (Solum 2004; Conley, O’Barr, 2005).

The problem of courtroom speech influence is the main focus in the course of legal rhetoric (Larson, 2012). In legal practice, one can more or less clearly see the cognitive and communicative aspects of the activity, the success of which in most cases depends on the skillful establishing the psychological contact with the people and on treating an individual as a person (Harste, 2016; Forsyth, Grabowski, 2015).

Forensic speeches influence the formation of judge's inner views, help the court to look deeper into all the circumstances of a case, comprehensively, fully and objectively investigate the circumstances, and find the truth in the case and make a right decision (Wilson, 2016). Thus, any court proceeding is a form of verbal communication (Feldman, Gill, 2017). This means of rhetorical communication is the convincing of judges and process participants of the correctness of the theses, put forward by the debate subjects, and the reasonableness of solutions put forward by them (Feldman, Gill, 2017; Michael, 2016).

Some lawyers consider legal rules and reasoning matter even in close cases (Reinhardt, 1995; Marshall, 2010; MacCormick, 1995). They believe there are good legal arguments and bad legal arguments and that the strength of the argument pushes the judge one way or another in choosing among plausible outcomes (Sarratt, 2004). Thus, in presenting their cases, lawyers consistently shape their talk in relation to the material being presented and to possible reaction of the audience (Chaemsaithong, 2017).

The content of courtroom speeches always has certain thoughts, ideas, or arguments that need to be delivered to the trial audience. They are inevitably associated with the personal attitude of people to the study results, ethical motivations, emotional perception of information, psychological state, cogency or non-cogency of the made conclusions (Henderson, 2016).

After exploring aspects of the logical and linguistic culture of trial participants, it became clear that issue of increasing the rhetorical culture of the society in general and oratorical skills of judicial speakers, in particular, stands out and needs to be addressed through oratory education, aimed at professional orientation (Robichaud, 2016; Goddard, 2016).

Based on this, it is important to identify the main speech-making criteria for a speech to be persuasive. The desire to convince the judges and strongly influence the intellect and emotions of the present in the courtroom citizens requires knowledge of complex language means that would allow for clear speech cohesion and would express the speech logic.

Therefore, the purpose of this study is to analyze the ways and methods of argumentation, language means of consistency and courtroom speech influence. According to this, the authors have set themselves the following objectives:

- $\quad$ to highlight the basic techniques of verbal behavior of a forensic orator;

- $\quad$ to characterize features of speech-making of public prosecutors, defense attorneys and judges; 
- to make recommendations on the selection and use of language means and the prevention of speech errors during a courtroom speech.

\section{Results}

Courtroom speech is one of the most difficult and critical moments for a prosecutor, defense counsel and judges. In order to confidently defend human rights and protect the interests of society, lawyer's words should be fair and conclusive. After all, the ability to skillfully prove the guilt or innocence of the defendant is a lawyer's professional duty. Thus, the influence of a forensic orator on the audience depends on the depth of legal knowledge, professional skills and the ability to speak in public (Sampson, 2014).

Persuasion can be achieved in two ways: rational and emotional (Włodarczyk, 2010). Expressive and emotional impact of a courtroom speech is achieved by the use of figurative and expressive language means, such as metaphors, antitheses, parallelism, hyperboles, similes, or irony. The methods of expressive and emotional impact include:

- addressing the court and the jury: Your Honor, Mr. Foreman, and Gentlemen!;

- $\quad$ the use of pronouns: You, Your;

- $\quad$ verbs of imperative and causative mood: ...bring your hearts and your homes and your intellects here, ... let us talk to you like men;

- $\quad$ expression of a personal attitude to the analyzed material: I say, I think.

A lawyer always strives to involve members of the court into the course of their thoughts, and for this purpose, he/she uses persuasion tricks (Paterson, 1983). By using the "inclusive" pronoun we, lawyer unites him/herself with the jury, places him/herself on one side, and at the same time opposes the prosecutor and his supporters with a pronoun they.

In order to keep the speech interesting, stimulate the attention of the audience and the reception of the message, the orator has to use rhetorical questions, which expressively convey affirmative or negative information. While arguing with the procedural adversary, they often turn to rhetorical questions, which allow convincingly deny in an expressive and emotional form the opposite point of view at an appeal to the court.

Another basic quality of a courtroom speech is a linguistic norm - there are scientifically proven and compulsory regulations of the use of words and their combination in the language. First, language has the semantic side of individual words and of the language structure, their full compliance with the presented arguments.

Laconic speech can be achieved through the exact expression of thoughts, their clear realization, and lack of excess words or wordiness. For example, wordiness is a common mistake in court: at the neighbors' request, speaks only positively; one kind of wordiness is a pleonasm, i.e., a combination of words, meaning the same thing: $a$ fair blonde.

There are techniques that are considered courtroom speech expression means and which enhance its emotional impact. These techniques include: 
- $\quad$ direct attention demand;

- $\quad$ the pause, which allows highlighting the following main aspects;

- $\quad$ vocal techniques (voice raising or lowering, changing the tempo);

- addressing the audience with a question, related to the

content of the speech, that intensifies and stimulates the audience's

attention;

- $\quad$ prior notice of the speech subject;

- $\quad$ unexpected break of a started thought;

- $\quad$ expressive language means (proverbs, sayings, vivid images,

humor);

gestures and movements.

\section{The compositional structure of a judge's courtroom speech}

The study is most interested in the final judge's address to the jury before they retire to the chambers to return a verdict, as it is this speech, which is one of the most important in the courtroom.

Parting words are a monologic pronouncement, but in fact, it is a deeply dialogical genre. Judges address using a narrative model, based on daily life and logic.

Parting words reflect different facets of a judge's language. First, the judge acts as a referee, which requires an impartial and fair coverage of the case. The notions of justice and fair trial are often featured in the judges' speeches. In this way, the judge convinces the jury to assess all of the witnesses with the same degree of fairness.

An important means of expressing logical relationships between the composite parts and separate statements are special means of communication, indicating the thought sequence (at first, primarily, then, I repeat, therefore, so), conflicting attitude (as has already been mentioned, therefore, due to this, according to), result, conclusion (so, in conclusion, summing up, it must be said).

\section{The compositional structure of a public prosecutor's courtroom speech}

Prosecutor's speech in court is the representation of the government, accusing the perpetrators and demanding their conviction and sentence. Therefore, the accusatory speech must be cogent not only for the court but also for all those present at the trial; it should contain a charge of educational influence and contribute to the eradication of the causes and conditions that give rise to crime.

The content and composition of a prosecutor's speech depend on the nature of the crime. The content of speech for the prosecution is determined by the topic of the oratorical speech, prosecutor's position in the case and the subject of forensic speech. Prosecutor's speech must not include a propensity to charge, but it does not mean that a prosecutor should be lenient to the crime. An important role in performing professional duties plays the prosecutor's conclusion in the pleadings, in which, as public prosecutors, they help the court fairly and reasonably solve a criminal case. By participating in courtroom debates and delivering an accusatory speech, prosecutors express those conclusions to which they came because of a criminal case cognizance and sum up the accusatory activity. Prosecutor's speech is one of the most critical stages of supporting accusations in court.

One of the prerequisites for an accusatory speech is its completeness and conciseness. 
No eloquence, none of the most expressive and correct arguments concerning the gravity of an offense will not be able to fill the gaps of the evidentiary part of a speech. Prosecutor must give a profound and comprehensive analysis of the criminal case materials and highlight all of the essential circumstances. At the same time, it should not be too ponderous or too lengthy, as a lot of talking and a lot to say are not the same things. Point is not in wordiness but in the speech consistency and thoroughness. Accusational speech should be emotional, passionate and exciting.

A prosecutor's speech should not be a routine, but an event in their life. Only with this attitude prosecutor's speech will reach the hearts of the audience, be able to influence their minds, convince and move the public opinion to fight crime. An emotional accusatory speech should also be rational and based on the collected and examined at the court hearing evidence.

An important quality of a speech for the prosecution is its intelligence and culture. On this depends the speech accuracy, expressiveness, logical consistency, and cogency. Every prosecutor's word must meet its etymological meaning and be pronounced according to the rules of phonetics. The "clerical language," such as struck in the face (instead of hitting the face), does not decorate, but impoverishes the accusational speech and makes it "banal."

The disadvantage of prosecutorial speeches in the analysis and evaluation of evidence is that the logical proof and evidence analysis is replaced by interpreting the testimony of a defendant, victim, witnesses or expert opinion. Such repetition only tires the audience in a courtroom with its monotony and does not convince anyone of anything. Forensic speaker's duty is to show the place and role of all the evidence in a case file and to assess it as a whole.

\section{The compositional structure of attorney's courtroom speech}

The speech for the defense can be broken down into three main parts: introduction, the main part, and a conclusion. The whole initial fragment of speech (from the micro text compositional organization to the speaker's inner sensations) does the task of establishing a communicative contact with the court.

The topic of a defense speech introduction, as in an accusational speech, may have different structural elements of courtroom speech: social and moral assessment of the case, the causes, and conditions that contributed to the commission of the crime, the characteristics of the accused.

The primary (main) part focuses on the speech topic and content. The main part of the speech is divided into three sections: narrative, rebuttal, statement, evidence, and arguments. Rules for the structure of the narrative are as follows: to find the most advantageous point of view to present, which will touch only upon the main and most credible facts, speak briefly, figuratively, remember that the interest to speech depends on the interest in the story.

It is unacceptable to build a defense on emphasizing the negative aspects of the victim's identity or negative moral qualities. Especially, one cannot humiliate the victim's dignity. If the victim's actions, in fact, contributed to the commission of a crime or provoked it, and it has a legal significance, this fact can be discreetly mentioned in the defense speech.

XLinguae, Volume 11, Issue 4, October 2018, ISSN 1337-8384, eISSN2453-711X 
Lawyer's speech must not use arguments, the failure of which is obvious. Cheating, lying, deliberate distortion of the obvious facts is deeply immoral. They are incompatible with the prestige and status of a lawyer as a person and as a qualified lawyer, performing humanitarian functions. While from the point of view of defensive efficiency, they represent a significant danger to the lawyer principal's fate. The discovered deception, even in the details undermines the credibility of all that they said at the trial. At the same time, the lawyer in the defense speech is not obliged to mention the circumstances that may harm the principal, if the prosecutor did not mention them. This also applies to the criticism of the charges, such as "what is not proven, cannot be used as the basis of prosecution" or "the version of the accused, not refuted by the prosecutor, should be recognized as true."

\section{The qualities of courtroom speech for cogency}

The persuasiveness of the judicial speech in many respects depends on the quality of arguments. Arguments have to be true, reliable and should not contradict each other. Their validity is checked by practice. They have to be sufficient for the proof, meaning that arguments must be strong, clear and convincing, not voluminous in the amount so that the jury could follow the thesis. The rhetoric learns: proofs should be multiplied not so much, how many to weigh; to reject arguments, which can be disproved.

Demonstration, or way of the proof, is a form of logical communication between arguments and the thesis. This logical reasoning is a set of conclusions at the removal of the thesis from arguments. To show - means to show that the thesis logically locates arguments and therefore is true.

For the judicial speech wide use of logical arguments, proofs are characteristic; thus the speaker aspires by means of convincing facts to make the necessary impact on the consciousness of listeners. To convince the audience - means to compel it to agree with opinion, views, and conclusions of the speaker and to induce to accept views of the speaker as own. "Technology" of belief is reduced making the audience the accomplice of the process of formation of a conclusion, which wants to affect it which acceptance from us is required. The judicial speaker has parts of the speech, and procedural and "logical proofs" (Reinhardt, 1995) so that persuasiveness of the speech increased in the process of expansion of its contents. First of all, to court, it has to be clear to listeners as the thought is formed, the proof of the speaker why it rejects one proof, others - considers reliable, the third - doubtful, contradictory. The judicial speaker as if leads audience searching him the truth, only a right conclusion on business, does it by the fellow traveler on this difficult way.

The talented speech, as a rule, embodies the unity of rational and emotional ways of knowledge. The speaker himself chooses the necessary ratio of these categories taking into account the content of performance and specifics of the audience. During the performance, the ratio rational and emotional can also change taking into account behavior and the reaction of listeners.

The emotional beginning expresses its sensual moments, subjective features that are quite often generating synchronous and similar feelings in the audience in the judicial speech. If the speaker forgets about the emotions of listeners, thereby he loses an important lever on the audience.

The judicial audience - is sensitive. There are no indifferent. Emotional influence of 
the speech is huge. As we lose that from a judicial tribune the speeches capable "a verb seldom are distributed much to burn down hearts,"

and often speeches are replaced with some hybrids out of boredom and idle talk (Koni 2000).

An emotional shade of the judicial speech convinces the speaker of correctness and justice of about what he speaks, his enthusiasm for contents of the speech, agitation before the forthcoming meeting with listeners. All this definitely already adjusts the speaker emotionally. Oratorical emotions have to be organic, natural. The truthfulness of thought is expressed in the truthfulness of emotions, the sincerity of the speaker. Sincerity and naturalness help to establish and constantly to keep in touch with the audience. However, the speech should not be overloaded with emotions, especially in court. It can arouse mistrust to the speaker and to the content of its performance. Replacement of arguments with emotions does not promote belief. During pronouncing the speech, it is necessary to control the emotions, feelings, to be able to operate them.

The judicial speech purposeful work, which assumes achievement of the planned effect, regular impact on addresses. Influence is a process of drawing attention listening to a subject of the speech with the purpose to make changes in views of the recipient of the message. The main level in the judicial speech is the organization of material, logical substantiality. The judicial speaker by means of convincing facts makes a rational impact on judges. If he does not feel afraid to raise sensitive issues and to find them the correct solution, his speech sounds convincing.

Expedient and unhindered application of language for communication provides quality of the speech: correctness, laconicism, expressiveness, originality, wealth.

\section{Correctness}

One of the main qualities of the judicial speech defining its efficiency is correctness, which assumes observance of the standard standards of the literary language. Language norms are the most widespread, the options of pronunciation, the use of words, spelling, and statement of punctuation marks accepted in public and speech practice and regulated by rules, word formations. Norms developed in language historically; they are the result of selection of the most suitable from among coexisting and reflect real tendencies of development of language. Standards of language are characterized by relative stability, all-obligation. Observance of the lexical norms providing word usage accuracy is important; orthoepic and the norms of an accent, causing unity of sound registration of the speech. Grammatical norms (morphological and syntactic) establish uniformity of forms of word change and connection of words in phrases and offers. Stylistic norms provide relevance in the speech emotionally, and functionally painted language means.

\section{Laconicism}

Some lawyers, authors of works about the judicial speech, consider that "laconicism of the speech is reached by the use of short phrases because they easier are perceived." Of course, short statements are perceived easier, than long constructions. However the best judicial speakers used and use difficult syntactic designs with 
participial and verbal adverb phrases, with homogeneous parts of the sentence; but, when speakers speak to the point, convincingly, the called language means promote manifestation of oratorical skill. Laconicism of the speech is reached by exact expression of thoughts, the existence of accurate formulations, and absence of the excess words, which are not bearing information, lack of verbosity and excess, inappropriate thoughts.

Speech accuracy is connected most often with word usage accuracy.

The accuracy of word usage depends on that, how the speaker knows the subject of the speech as far as it is erudite, whether he is able to think logically, whether he knows laws of language, its rules. Thus, the accuracy of the speech is defined:

- $\quad$ knowledge of a subject;

- $\quad$ the logic of thinking;

- $\quad$ ability to choose proper words (Sanders, 1987).

Violation of a logical sequence, the absence of logic in a statement results in inaccuracy of the speech.

We will consider, in what cases speech accuracy because of insufficient knowledge of features of language is broken. Are most typical from them:

- $\quad$ the use of words in value unusual for them;

- the polysemy which isn't eliminated with a context

generating an ambiguity;

- a mixture of paronyms, homonyms.

Each significant word carries out nominative function, i.e., calls a subject or its quality, action, a state. It obliges speaking to pay attention to word meaning; it is correct to use them. The negligent relation to language can lead to misunderstanding, incorrect actions, conclusions, to a violation of speech ethics, and sometimes even to quarrel.

\section{Expressiveness}

The brevity of the speech has to be combined with its deep contents that promoted by emotionality and expressivity. Emotions are caused by the material of judicial speech (Corder 1983). The expressivity (expressiveness) of the performance of the speaker depends on the independence of his thinking, on its interest in about what speaks; from the ability to control the speech; from conscious intention to speak expressively. The expressive speech causes interest in judges and citizens who are present at the courtroom, maintains interest in a conversation subject. Creation of expressivity and emotionality is served by language means by means of which the speaker expresses the emotional and strong-willed relation to a subject of the speech and by that influences emotions of jurors and the citizens hearing case.

These are various graphic means of expression. However, each graphic means of expression is pertinent in the judicial speech in that case when helps to strengthen sounding of argument, and also to express an important thought, to transfer it to the court, the defendant or citizens who are present at the courtroom. Use of rhetorical receptions for the sake of embellishment, the prettiness of the speech weakens its logical aspect, reduces its persuasiveness.

\section{Originality}

Especially valuable quality of the public speech is the identity (originality) - ability to 
speak about the most familiar facts by the own words, without using speech stamps. Stamps are the sample, often used in the speech and bothered words and expressions with semantics, which grew dull from the frequent use. People use stamps thoughtlessly, on a habit, depriving thereby the speech of identity. Still, quite recently, there were widespread in the speech such stamps: active fighter; in a warm, friendly situation; great success; indelible impression; worthy meeting; sharp criticism; wide scope; rough, prolonged applause.

Now, these stamps are used in the speech much less often. In the legal speech stamps unjustly, from hooligan motives are frequent; to kick with feet; to appoint business hearing; put production to stop, etc. They represent the wrong, wrong connections of words: in the first stamp is superfluous unjustly (it is necessary: from hooligan motives); in the second the superfluous - feet (it is necessary: to kick); in the third norms of management are broken (it is necessary: to appoint hearing of the case).

\section{Wealth}

One more important, simply necessary quality of the convincing speech is its wealth or a variety. This maximum use of various means of language is necessary for effective information transfer. If in the speech, the same language means (words, phrases, and the same syntactic designs) if in it a big lexicon, the active structure of models of phrases and offers, such speech call rich or various.

Speaking it is necessary to have a sufficient vocabulary to express the thoughts accurately and clearly. It is important to care constantly of expansion of this stock, to try to use the richness of the native language. The richness of language is also defined by a semantic saturation of the word, i.e., its polysemy. Important, whether the word is chosen for expression of thought? Whether the listener about what there is a speech what means the speaking understands?

Most often in the speech, one of the values of the multiple-valued word is realized. If it were different, people often would not understand each other or misunderstand. However, the polysemy can be used as the reception of enrichment of the contents of the speech.

\section{Discussion}

The standard of speech begins where the knowledge turns into skill as having got used to speaking in daily communication as it is necessary, in the trial the lawyer can repeat habitual mistakes (Searle, 1971; Solum, 2004; Werhan 2004; Conley, O’Barr, 2005; Marshall, 2010; Gibbons, 2014). Therefore, it is necessary to work constantly on the increase of the standard of speech, to seek to coordinate knowledge to speech skills.

One can note that foreign studies of courtroom discourse as a kind of legal discourse mainly present an analysis of monologue statements (Reinhardt 1995; Marshall, 2010). Analysis of legal discourse extends beyond text analysis. The scientists' attention is not just paid to style and logic-forming ways to create discourse (Tiersma, 1999), but also pragmatic factors - the situation of communication, social and historical context, national and cultural background, status characteristics and intentions of the participants of communication, as well as their individual 
characteristics, including psychological, emotional, linguistic and mental ability, and age (Gee, 2015). Analyzing public statements of former, Swedish foreign minister, S. Moberg (2016) indicates that all abovementioned factors can be used in order to mask discursive structures and strategies.

The authors share the scientific thought known of professional forensic orators on courtroom rhetoric theory (Gibbons, 2014) that the speaker who appears in court should use words according to the circumstances of the case and their official position.

They also believe that each courtroom speech, regardless of the procedural position of the trial participant, delivering it, has to meet the requirements of criminal procedural law and the basic principles of forensic oratory (Chaemsaithong, 2015).

In our opinion, forensic orator's speech (accusational or defensive) are based strictly on the collected evidence, according to relevant legal documents with a specific language style, content, and form of presentation. The forensic speaker has to compile and combine documents (very often different in structure and grammatical form) and develop their own language and speech style (but not on your own - professionally, as required by the case circumstances) without accidentally violating the essence of the case.

Analysis of the literature allows for the conclusion that the dialogic interaction in a courtroom, including the interaction with trial participants, is a wide field for further researches, aimed at to specifying the principles of a judicial discourse, based on a variety of extra-linguistic factors.

\section{Conclusion}

Forensic speech can be characterized by widespread use of logical arguments and evidence; at the same time, the orator, by means of convincing facts, has the right impact on the listeners' minds. The speech has to convince the audience, and then get it to agree with the opinion, views, and conclusions of the speaker and to stick to the speaker's views. The "technology" of persuading narrows down to making the audience complicit in making a conclusion, which should influence it and which is required. Forensic orator places parts of his speech, as well as procedural and logical evidence so that the speech cogency increased with the showdown of its content. It should be clear for the audience and judges how a thought is formed, speaker's proof, why they reject some evidence, while other arguments are reliable, and other is questionable, contradictory. Forensic speaker as if leads the audience in search of the truth, the only correct conclusion on the case, makes it their companion on this difficult path.

The main purpose of speaker's presentation is to influence the court and to the audience through showdown of new facts, placing the corresponding emphasis and, most importantly, through reference to the audience's imagination and emotions.

The success of forensic orator's speech is determined by purposeful, persistent desire to improve themselves, to learn how to use words, as speech culture is an indispensable culture element of a trial. An analysis of scientific papers on speech culture allows us to prove that speech culture begins where knowledge becomes a skill. Therefore, it is necessary to constantly work on improving the speech culture and try to connect knowledge with language skills.

Communicative qualities of the judicial speech: clarity (availability, simplicity), 
accuracy, persuasiveness, logicality, emotionality, and expressivity allow the judicial speaker to make the speech on the present evidential. The qualities of the judicial speech considered above are in close interrelation and in dialectic unity.

\section{Bibliographic references}

BEDNAREK, G. A. 2016. Polish VS. American courtroom discourse: inquisitorial and adversarial procedures of witness examination in penal trials. What court interpreters need to know about witness examination in criminal trials under disparate legal systems to provide high-level interpreting services in the light of the directive 2010/64/EU of the European Parliament and of the Council of 20 October 2010? Comparative Legilinguistics, vol. 19, pp. 77-116.

CHAEMSAITHONG, K. 2017. Use of voices in legal opening statements. Social Semiotics, pp. 1-18.

CHAEMSAITHONG, K. 2015. Positioning self and others in the courtroom: Person markers in the opening statement. Poznan Studies in Contemporary Linguistics, vol. 51, n. 1, pp. 1-25.

CONLEY, J. - O'BARR, W. 2005. Law, language, and power. Chicago: University of Chicago Press.

CORDER, S. P. 1983. Strategies of communication. In Strategies in interlanguage communication, eds. C. Faerch and G. Kasper. London: Longman, pp. 15-19

COULTHARD, M. 2014. An introduction to discourse analysis. London and New York: Routledge.

FELDMAN, A. - GILL, R. D. 2017. Echoes from a Gendered Court: Examining the Justices' Interactions During Supreme Court Oral Arguments.

FORSYTH, R. S. - GRABOWSKI, Ł. 2015. Is there a formula for formulaic language?. Poznan Studies in Contemporary Linguistics, vol. 51, n. 4, pp. 511-549.

GODDARD, C. 2016. Learning to fly: The prospects for legal linguistics in the academic curriculum... and beyond. Language in the Negotiation of Justice: Contexts, Issues and Applications, pp. 279.

HARGITT, S. 2013. What could be gained in translation: legal language and lawyerlinguists in a globalized world. Indiana Journal of Global Legal Studies, vol. 20, n. 1, pp. 425-447.

HARSTE, G. 2016. Law and Intersystemic Communication: Understanding 'Structural Coupling'. Routledge.

HENDERSON, L. M. 2016. Crisis in the Courtroom: The Conditions of Possibility for Ruptures in Legal Discourse.

GARVER, N. 1998. Dennis Patterson, Law \& Truth. The Journal of Value Inquiry, vol. 32, n. 3, pp. 4.

GEE, J. 2015. Social linguistics and literacies: Ideology in discourses. Routledge.

GIBBONS, J. 2014. Language and the law. London and New York: Routledge.

GOODRICH, P. 1984. Law and language: An historical and critical introduction. Journal of Law and society, vol. 11, n. 2, pp. 173-206.

KJÆR, A. L. 2017. Comparative law and language in the case law of the European Court of Human Rights. International Journal for the Semiotics of Law.

LARSON, Ch. 2012. Persuasion: Reception and responsibility. Wadsworth: Cengage

XLinguae, Volume 11, Issue 4, October 2018, ISSN 1337-8384, eISSN2453-711X 
Learning.

MACCORMICK, N. 1995. Defeasibility in law and logic. In Informatics and the Foundations of Legal Reasoning. Springer Netherlands, pp. 99-117.

MARSH, I. - COCHRANE, J. - MELVILLE, G. 2004. Criminal justice: An introduction to philosophies, Theories and practice. London: Routledge.

MARSHALL, W. 2010. Judicial takings, judicial speech and doctrinal acceptance of the model of the judge as political actor. Duke Journal of Constitutional Law \& Public Policy, vol. 6, n. 1, pp. 1-35.

MATOESIAN, G. 2017. Communication in investigative and legal contexts: integrated approaches from forensic psychology, linguistics and law enforcement, edited by Gavin Oxburgh, Trond Myklebust, Tim Grant and Rebecca Milne.

MATTILA, H. E. 2016. Comparative legal linguistics: language of Law, Latin and modern lingua francas. Routledge.

MICHAEL, C. O. 2016. Communication of an interpreter and fair trial under Nigerian criminal justice system. International Journal of Legal Discourse, vol. 1, n. 1, pp. 213233.

MIKHAIL, J. 2011. Elements of moral cognition: Rawls' linguistic analogy and the cognitive science of moral and legal judgment. Cambridge University Press.

MOBERG, S. 2016. What is all the talk about? A comparative analysis of linguistic strategies in the speeches of former Swedish foreign minister. Journal of Applied Journalism \& Media Studies, vol. 5, n. 2, pp. 219-243.

MORRIS, C. 2000. Morals, manners, and law. The Journal of Value Inquiry, vol. 34, n. 1 , pp. 45-59.

OXBURGH, G. 2015. Communication in investigative and legal contexts: integrated approaches from forensic psychology, linguistics and law enforcement. John Wiley \& Sons.

PATERSON, A. 1983. The law lords. Springer.

PATERSON, A. 2011. Lawyers and the Public Good: Democracy in Action?. Cambridge University Press.

REINHARDT, S. 1995. Judicial speech and the open judiciary. Loyola of Los Angeles Law Review, vol. 28, n. 3, pp. 805-814.

ROBICHAUD, D. 2016. Linguistic justice: international law and language policy.

ROGERS, R. - SCHAENEN, I. - SCHOTT, C. - O'BRIEN, K. - TRIGOSCARRILlO, L. - STARKEY, K. - CHASTEEN, C. C. 2016. Critical discourse analysis in education: A review of the literature, 2004 to 2012. Review of Educational Research, vol. 86, n. 4, pp. 1192-1226.

SAMPSON, G. 2014. Complexity in language and in law. Poznan Studies in Contemporary Linguistics, vol. 50, n. 2, pp. 169-177.

SANDERS, R. 1987. Cognitive foundations of calculated speech: Controlling understandings in conversation and persuasion. Albany, NY: SUNY Press.

SARRATT, W. D. 2004. Judicial Takings and the Course Pursued. Virginia Law Review, pp. 1487-1535.

SEARLE, J. 1971. Speech acts: An essay in the philosophy of language. Philosophy \& Rhetoric, vol. 1, pp. 59-61.

SIMPSON, R. M. 2016. Defining 'Speech': Subtraction, Addition, and Division. Canadian Journal of Law \& Jurisprudence, vol. 29, n. 02, pp. 457-494.

SOLAN, L. 2017. The Interpretation of Legal Language. Annual Review of 
Linguistics, vol. 4, n. 1.

SOLUM, L. 2004. Procedural justice. Washington, DC: Georgetown University Press. STRAUBER, I. L. 2016. Televising Supreme Court Oral Argument?. Law, Culture and the Humanities, vol. 12, n. 2, pp. 243-277.

TIERSMA, P. 1999. Legal language. Chicago: University of Chicago Press.

TITSCHER, S. - WODAK, R. - MEYER, M. - VETTER, E. 2013. Methoden der Textanalyse: Leitfaden und Überblick [Methods of text analysis: Guide and review].

Opladen: WestdeutscherVerlag.

WAGNER, A. - CHENG, L. (Eds.). 2011. Exploring courtroom discourse: The language of power and control. Ashgate Publishing, Ltd..

WERHAN, K. 2004. Freedom of speech: A reference guide to the United States Constitution. Westport, Connecticut: Greenwood.

WILSON, R. A. 2016. Expert evidence on trial: Social researchers in the international criminal courtroom. American Ethnologist, vol. 43, n. 4, pp. 730-744.

WITCZAK-PLISIECKA, I. 2009. A note on the linguistic (in)determinacy in the legal context. Lodz Papers in Pragmatics vol. 5, n. 2, pp. 201-226.

WŁODARCZYK, M. 2010. Infinitives in the 1820 Settler Letters of Denunciation: What can a Contextualised Application of Corpus-Based Results Tell us About the Expression of Persuasion?. Poznań Studies in Contemporary Linguistics, vol. 46, n. 4, pp. 533-564.

Words: 6034

Characters: 39029 (21.68 standard pages)

Philosophy doctor in law Gasimov Arastun Aliyar oglu

Department of Criminal Procedure

Baku State University

Baku, Str. Z.Xalilov, 23

Azerbaijan

haci-arastun@rambler.ru 